\title{
Evaluation of Dry Eye Symptomatology at Patients with Keratoconus
}

\author{
MIHAELA MONICA CONSTANTIN ${ }^{1}$, CATALINA CORBU ${ }^{1,2}$, VASILE POTOP², MIRUNA BURCEL'2, SORIN MOCANU³, \\ GABRIELA IONITA3* \\ 1Oftaclinic Grup, Department of Ophthalmology, 2B Marasesti Blvd., 030987, Bucharest, Romania \\ ${ }^{2}$ Carol Davila Faculty of Medicine, Emergency Hospital of Ophthalmology, Alexandru Lahovari Sq., 010464, Bucharest, Romania \\ ${ }^{3}$ Ilie Murgulescu Institute of Physical Chemistry of the Romanian Academy, 202 Splaiul Independentei, 060021, Bucharest, \\ Romania
}

\begin{abstract}
The aim of this study was firstly to determine and quantify the dry eye symptomatology of patients with keratoconus, in comparison with those without this condition and secondly to evaluate the suitability of the spin probe method of electron paramagnetic resonance spectroscopyin analysis of tears secretion. As such were considered two groups of patients for evaluation: 36 cases with keratoconus (keratoconus group) and 36 cases without ocular disease (control group). Besides general ophthalmological examination we have conducted Schirmer test I, tears break-up time (BUT) and quantify the answers about dry eye symptomatology to establish ocular surface disease index (OSDI). We have included a prospective correlation of ophthalmologic parameters with parameters of the spin probes added in tear secretions collected from both groups of patients. The results show that the value of OSDI for patients with keratoconus was higher $(41.07 \pm 23.68)$ than the corresponding value of the control group (14.63 \pm 9.27$)$. Also, the patients with keratoconus present lower mean values for BUT and Schirmer tests comparatively with the cases from control group. The electron paramagnetic resonances spectra of the spin probe CAT16 in tear secretions obtained from patients revealed changes that can be related with ophthalmologic parameters.
\end{abstract}

Keywords: break-up time, Schirmer test, electron paramagnetic resonance spectroscopy

: Keratoconus is corneal ectasia characterized by lesions at every corneal layer with a diagnosis relatively easy to establish using specific examination (keratometry, corneal topography, pachymetry), but the elements related to its occurrence and progression are still unclear [1]. The latest studies underline the role of inflammatory factors and tear film proteins concentrations changes in the disease progression [1, 2]. These inflammatory elements also occur in the physiopathology of the dryeye syndrome (DES) which is met frequently at keratoconus patients. Some studies reveal that dry eye syndrome is a determining factor for keratoconus progression. The dry eye syndrome is presented in $81.5 \%$ of keratoconus patients and among them $70 \%$ have higher tear film instability. According to International Dry Eye Workshop 2007, DES is defined as a multifactorial tear film and ocular surface disease that have as a result the appearing of discomfort, visual acuity degradation and tear film instability with potential injuries of ocular surface. Some studies estimate that as much as $30 \%$ of world populations are affected $[1,2]$. Among the patients with keratoconus and dry eye some common symptoms are present, such as burn and foreign body sensation, itching, red eye, photophobia, blurred vision, which are amplified by wind, hotter, lower humidity, irritating factors (smoking), activities that requires attention (reading, working at computer, driving).

This syndrome is associated with quantitative or qualitative deficiency of the tear film. The inflammatory process affecting the tear film homeostasis is the base for the physiopathology of this disease [3]. The composition and the tear film stability changes determine ocular surface inflammation, hyper osmolarity of tear film that determines destruction of intercellular junction and increasing the epithelial cell apoptosis [4]. Recent studies reportchanges of the protein profile in the tear film for patients with keratoconus. Lysozyme, lactoferrin and albumin are the main proteins that present changes in keratoconus and in dry eye syndrome. The concentration of these proteins in

the tear film depends on the age and the eye health. Clinical studies often report thatDES and keratoconus significantly alters tear physiology $[5,6]$. For instance, elevation of the albumin level is frequently met in DES and indicates vascular extravasations. In the same time, the tear film of the patients with dry eye has a lower content of lactoferrin and lysozyme. The levels of oxidative stress markers such as superoxide dismutase (SOD) glutathione peroxidase (GPX) present in tears may present alterations in DES and keratoconus [7].

Usually the proteins changes in the tear film composition can be evidenced and monitored by biochemical analysis. The electron paramagnetic resonance (EPR) spectroscopy represents a versatile method to evidence formation of reactive radical species and to prove changes in complex systems by analyzing the behavior of stable free radical. We previously evidenced the formation of reactive radical species in simplified systems for photo oxidative crosslinking at patients with keratoconus [68]. In this paper we analyzed the spectral parameters changes induced in the EPR spectra of a cationic spin probe (N-oxy1-2,2,6,6tetra-methyl-4-dimethyl-amino-piperidine-cethyl bromid Figure 1)) in tear secretions. The molecular probes are stable free radicals whose EPR spectral parameters depend on their interaction with other substances (especially protein) and by the hydrophobic/hydrophilic properties of medium [9-11]. Correlation of the EPR parameters changes with ophthalmic parameters may recommend electronic resonance paramagnetic (EPR) spectroscopy as a method for qualitative evaluation in DES.

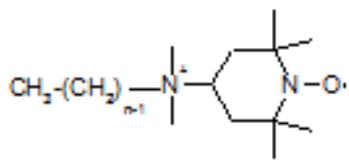

CA T $n$
Fig. 1. The structure of CAT16

\footnotetext{
*email:ige@icf.ro
} 


\section{Experimental part}

A number of 72 patients recruited from Oftaclinic Grup were divided in two groups: the control group consisting of 36 patients without keratoconus and the keratoconus group consisting of 36 patients with keratoconus in different stadia. Each patient underwent a complete ophthalmological examination. The keratoconus stadium was established based on Krumeich - Amsler classification [12]. To establish the DES diagnosis, the values of the ocular surface disease index (OSDI), Schirmer test I, tear breakup time (BUT) were determined for all patients. OSDI was established based on the answers at the questions about dry eye symptomatology (light sensibility, gritty, sore eyes, blurred vision, poor vision), factors that amplify this (reading, night driving, computer working or watching television) and environmental conditions (low humidity, conditioner air or windy condition). The answers were quantifying on a scale from 0 to 4 and the sum of them was multiplied by 25 and divided to the number of answers. The value of Schirmer test I was determined at 5 minutes after the Schirmer strip was placed on the eye lead without anesthesia. The value of BUT were recorded after instillation of fluorescein and represent the number of seconds between the last blink and the appearance of the first spot in the tear film.

For EPR measurements, approximately $25 \mu \mathrm{L}$ of tear secretion were collected from patients that consent to provide such samples. The EPR spectra of the spin probe N-oxy1-2,2,6,6-tetra-methyl-4-dimethyl-amino-piperidinecethyl bromid (CAT16) were recorded in the tear samples provided both by patients with and without keratoconus. A stock solution of CAT16 $10^{-2} \mathrm{M}$ in ethanol was prepared and a suitable volume was evaporated in a vial in order to final achieve concentrations of $5 \times 10^{-4}$ or $2.5 \times 10^{-5} \mathrm{M}$ of the spin probe in the tear secretion collected from patients. The EPR spectra were recorded on aJ EOL FA 100 spectrometer operating at a frequency modulation of $100 \mathrm{kHz}$, microwave power of $0.998 \mathrm{~mW}$, sweep time of $480 \mathrm{~s}$, modulation amplitude of $1 \mathrm{G}$, time constant of $0.3 \mathrm{~s}$, and a magnetic field scan range of $100 \mathrm{G}$.

\section{Results and discussions}

Demographic data show that the mean age of the control group was $34.16 \pm 10.04$ years (range from 14 to 49 years) and for the keratoconus group was $26.05 \pm 7.88$ years (range from 13 to 49 years). We note the predominance of male gender in the keratoconus group (28 male $/ 8$ female) and gender equality in the control group (18 male/18 female). The distribution of patients with keratoconus was as follows: 5 cases - stadium I, 12 cases - stadium II, 5 cases - stadium III and 14 cases stadium IV. The OSDI records have a lower value in the control group than in the keratoconus group. Thus, the mean value of OSDI in the control group is $14.63 \pm 9.27$ (range from 0 to 33.28 ), while $30 \%$ of patients have values higher than 20 . In the case of keratoconus group, the mean value for this parameter is $41.07 \pm 23.68$ (range from 9 to 48) and it was observed that in $36 \%$ of patients show values lower than 20.

The values of Schirmer and BUT tests are lower at patients with keratoconus comparatively with the patients without keratoconus (table 1).

The statistical analysis evidences a significant positive correlation between the age and OSDI values $(0.4968$ for control group and 0.4570 for keratoconus group). A significantly moderate negative correlation was observed between the age and BUT $(-0.3451)$ or Schirmer test values (- 0.5333) at patients with keratoconus. Table 2 presents the percentages of normal and decreased values for these ophthalmologic parameters for control and keratoconus groups. We observe that more than $80 \%$ patients with keratoconus have smaller Schirmer or BUT values than normal and for $75 \%$ of these patients both values are lower.

\begin{tabular}{|l|c|c|c|c|}
\hline \multirow{2}{*}{ Parameter } & \multicolumn{2}{|c|}{ Control Group } & \multicolumn{2}{c|}{ Keratoconus Group } \\
\cline { 2 - 5 } & Mean & Range & Mean & Range \\
\hline OSDI & $14.63 \pm 9.27$ & $0-33.28$ & $41.07 \pm 23.68$ & $9-48$ \\
\hline Schirmer test & $16.8 \pm 5.71$ & $3-25$ & $9.44 \pm 6.17$ & $0-25$ \\
\hline BUT & $9.5 \pm 4.80$ & $2-20$ & $4.77 \pm 2.61$ & $1-10$ \\
\hline
\end{tabular}

Table 1

THE QUALITATIVE AND QUANTITATIVE TESTS VALUES FOR DRY EYE

OSDI - ocular surface disease index; BUT - breakup tear time

\begin{tabular}{|c|l|l|l|l|}
\hline Group & Values & Schirmer test & BUT & $\begin{array}{c}\text { Association of lower values } \\
\text { for BUT and Schirmer test }\end{array}$ \\
\hline \multirow{2}{*}{ Control } & Normal & $64.44 \%$ & $63.88 \%$ & \\
\cline { 2 - 5 } & Lower & $30.55 \%$ & $27.77 \%$ & $11.11 \%$ \\
\hline \multirow{2}{*}{ Keratoconus } & Normal & $19.44 \%$ & $11.11 \%$ & \\
\cline { 2 - 5 } & Lower & $80.55 \%$ & $88.88 \%$ & $75 \%$ \\
\hline
\end{tabular}

Table 2

THE DISTRIBUTION OF THE VALUES SCHIRMER AND BUT TESTS FOR CONTROL AND KERATOCONUS GROUPS

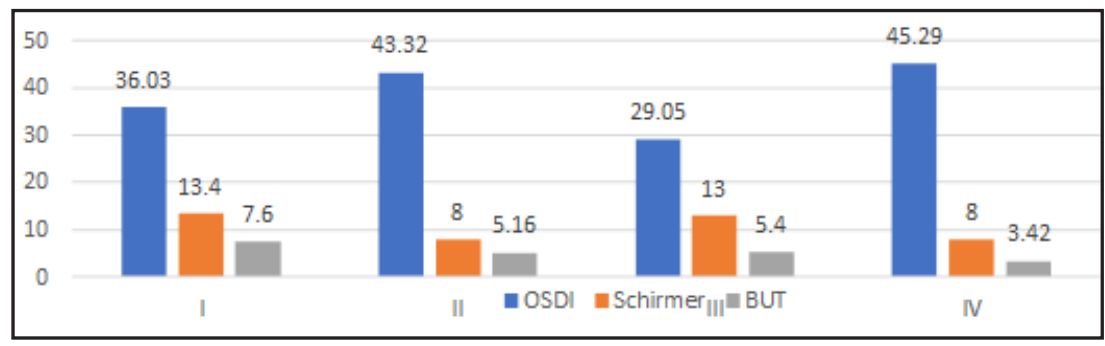

Fig. 2. OSDI, Schirmer test, BUT values on keratoconus stadium 
The figure 2 shows that the patients with advanced stadium of keratoconus have lower values especially for BUT test.

The statistical analysis evidence a negative significantly correlation between BUT value and keratoconus stadium $(-0.5372)$ and no significant correlations between OSDI, Schirmer test values and keratoconus stadium $(0.1773$, respectively -0.1862 ). A moderate significant negative correlation was obtained for OSDI and Schirmer test values $(-0.3867$ for control group and -0.3414 for keratoconus group). Also, we obtained a significantnegative correlation for OSDI and BUT values (- 0.5892).

The novelty element of this study is represented by the association of clinical methods already known and presented above with data provided by EPR spectroscopy which is often used to investigating biological or biochemical systems either by spin labeling or spin probes methods $[13,14]$. In this study we used a cationic spin probe (CAT 16) that can interact with the components of the tear secretion. In a series of studies, we investigated the behavior of this spin probe in solutions of albumins and we found that this probe binds to the albumin in the sites that are exposed to the protein/water interface due to its ionic properties $[15,16]$. The EPR spectrum of CAT16 in concentration $5 \times 10^{-4} \mathrm{M}$ exhibits three lines both in water (spectrum notshown) and in tear secretions. The spin probe CAT16 senses similar polarities in the tear samples (distance between the first and the third lines is almost constant). Qualitatively, information about the medium viscosity of tears secretion can be obtained from analysis of the middle line width and the ratio between the heights of the line arising at the high field and the central line from the EPR spectrum of CAT16. The components of the tear secretions, especially those with high molecular weight, such as proteins lead to an increased viscosity of tears compared with water $[17,18]$. Figure 3 shows the spectrum of CAT16 in tears secretion from a patient with normal Schirmer and BUT values (a), the spectrum of a patient with $15 \mathrm{~mm}$ value for Schirmer test and 5 seconds value for BUT (b) and the spectrum of a patients with 7 $\mathrm{mm}$ value for Schirmer test and 4 seconds value for BUT (c). The width of middle lines have the following values 1.75 G (a), 1.84 G (b) and 1.86 G (c), and the ratio between the height of the central line and the one of the line arising at higher magnetic field have the following values: 1.77, 1.61 and 1.51, respectively. In the case of the spin probe CAT16 in water the central line width is $1.7 \mathrm{G}$ and ratio between the central and the high field line is 1.91 .

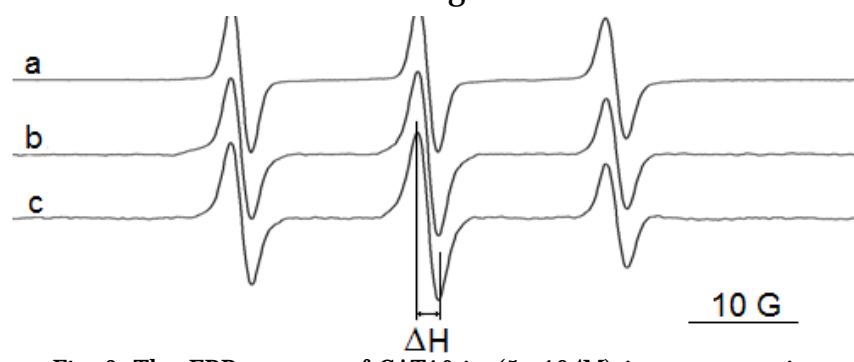

Fig. 3. The EPR spectra of CAT 16 in $\left(5 \times 10^{-4 M}\right)$ in tear secretions

A lower concentration of the spin probe (e.g. $5 \times 10^{-5} \mathrm{M}$ ) is more suitable to report changes occurring in the tear secretions. In this case the EPR spectrum is composed of two components. The major component weakly immobilized corresponds to the complex spin probe/ protein while the other component corresponds to the spin probe unbound and characterized by a rapid dynamic. For instance, Figure 4 shows a collection of EPR spectra of CAT16 $\left(2.5 \times 10^{-5} \mathrm{M}\right)$ in tear secretion obtained from patients with DES. Most likely the immobilized component from the EPR spectra is represented by the complex of the spin probe with the albumin from tear secretion, as the EPR spectra of CAT16 in solutions of lactoferrin, lysosyme immuno- $\gamma$-globuline are the same as in water.

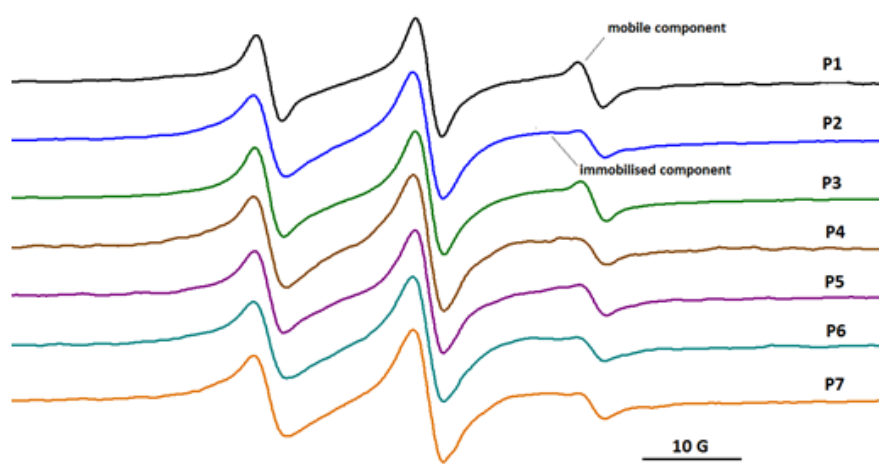

Fig. 4. The EPR spectra of CAT16 $\left(5 \times 10^{-5} \mathrm{M}\right)$ in tear secretions

The values of ophthalmologic parameters and the broadening of the central lines from the EPR spectra of CAT 16 in tear secretions are presented in table 3 for 7 patients. We notice that the broadening of the central line from the EPR spectra can be qualitatively correlated with the dry eye severity, especially expressed by the Schirmer test. Thus, for high values of Schirmer test, the broadening of the central line in EPR spectrum is lower.

Table 3

THE OPHTHALMOLOGIC PARAMETERS OF PATIENTS WITH DRY EYE SYNDROME AND BROADENING OF THE CENTRAL LINE $(\Delta \mathrm{H})$ IN THE EPR SPECTRA OF CAT16 SPIN PROBE

\begin{tabular}{|l|l|l|l|l|}
\hline No. & OSDI & Schirmer test & BUT test & $\Delta \mathrm{H}(\mathrm{G})$ \\
\hline P1 & 33.33 & 15 & 5 & 2.70 \\
\hline P2 & 59.09 & 7 & 4 & 3.21 \\
\hline P3 & 20.83 & 10 & 3 & 2.91 \\
\hline P4 & 31.25 & 10 & 5 & 3.21 \\
\hline P5 & 45.83 & 15 & 5 & 2.84 \\
\hline P6 & 56.29 & 9 & 3 & 3.14 \\
\hline P7 & 36.36 & 8 & 3 & 3.06 \\
\hline
\end{tabular}

In our study, it was noticed that the dry eye symptoms manifested through irritation, burns, foreign body sensation, and reflected by high levels of OSDI, were accentuated at patients with keratoconus, most of them having an advanced stage in their condition evolution. For both clusters of analyzed patients, OSDI values are correlated with age. Also, a significant negative correlation has been found between BUT and OSDI values. Objective data output of BUT and Schirmer tests are more reduced for patients with keratoconus, $75 \%$ of them showing, in our study, low values for both tests, like the study conducted by Carracedo $G$ et. all [1], in which $80 \%$ of the patients with keratoconus shows dry eye symptoms.

Moreover, the statistical analysis highlights a significant negative correlation between BUT and keratoconus stadium. The lower BUT values observed at the patients in advanced stadium of keratoconus may indicate the abnormal distribution of lacrimal tear film, conditioned by the conical shape of cornea. In the same time the lacrimal tear film instability is the result of mucin secretion alteration and diminution of glycosaminoglycans quantity $[1,19]$.

Some studies highlight the role of inflammatory factors in the evolution of keratoconus as it is suggested by the 
protein tear profile with low levels of lactoferrin and high levels of albumin $[19,20]$. In the absence of biochemical analysis of tear probes we investigated the potential of EPR spectroscopy in qualitative evaluation of DES. Thus, the results of this study revealed that the broadening of the central line and the increase value for the ratio between the heights of the central line and the line from the high magnetic field of the CAT 16 EPR spectrum correspond to lower BUT and Schirmer values.

\section{Conclusions}

The correlation of ophthalmic parameters such as BUT and Schirmer test with spectral parameters of spin probe in tear secretion can provide indirect indication of the dry eye syndrome. However, to validate this method a correlation with biochemical analysis of tears secretions is necessary. Further studies will be focused on using the qualitative information provided by EPR spectroscopy in monitoring the evolution of patients with DES and finding an optimal therapeutic formula.

Acknowledgement: This work was supported by a grant of the Romanian National authority for Scientific Research and Innovation, CNCS/CCCDI. UEFISCDI, projectnumber PN-III-P ${ }_{2}-2.1-P E D-2016-0187$, within PNCDI III

\section{References}

1.CARRACEDO G., RECCHIONI A., ALEJ ANDRE- ALBA N., J IMENEZ A., MOROTE I., PINTOR J., Curr. Eye Res. 40, nr. 11, 2015, p. 1088. 2.DIENES L., KISS HJ ., NAGY ZZ., ACOSTA M. C., GALLAR J ., KOVACS I., PLOS ONE 10, nr. 10, 2015, e0141621

3.LEMP M. A., BAUDOUIN C., BAUM J., DOGRU, M, FOULKS, G.N. , KINOSHITA, S., LAIBSON, P., MCCULLEY, J., MURUBE, J., PFLUGFELDER S.C., ROLANDO, M., TODA I, The Ocular Surface, 5, nr. 2, 2007, p 75
4.SMITH J ., NICHOLS, K. K., BALDWIN, E.K., Cornea, 27, nr 6, 2008, p. 656 The Ocular Surface, 5, $\mathrm{nr}$ 2, 2007, p 108.

5.HINDERBERGER D., Top. Curr. Chem. 321, 2012, 67-89.

6.CANTEMIR, A., ALEXA, A.I., CIOBICA, A. TOADER, E., BALMUS, I.M., COJOCARU, S.I., CHISELITA, D., COSTIN, D. Rev. Chim. (Bucharest), 67, no. 9, 2016, p. 1725.

7. ALEXA, A.I., CANTEMIR, A., CIOBICA, A., GARDIKIOTIS, I., ANTIOCH, I., HONCERIU, C., ZAMFIR, C. L., POROCH, V., Rev. Chim. (Bucharest), 68, no. 1, 2017, p.90.

8.CONSTANTIN, M.M., CORBU, C., IONITA, G., Rev. Chim.(Bucharest), 61, no. 5, 2010, p. 495

9.SMITH J. A., ALBETZZ J., BEGLEY CCAFFERY B., NICHOLS K., SCHAUMBERG D., SCHEIN O., The Ocular Surface, 5, Nr. 2, 2007, p 93. 10.YEH S., SONG XJ ., FARLEY W., LI D. Q., STERN M. E., PFLUGHEDER S. C. Invest Ophthalmol Vis Sci; 44, nr. 1 2003p. 124.

11.ROGOZEA A., MATEI I., TURCU I. M., IONITA G., SAHINI V. EM., SALIFOGLOU A., J. Phys. Chem. B 116, nr. 49, 2012, p. 14245.

12.RABINOWITZY.S. , KERATOCONUS. Surf Ophthalmol.1998 42 nr. 4, p. 297.

13.BERLINER LJ . Eur Biophys J. 39, 2010 p. 579

14.MARCUS A. HEMMINGA,LAWRENCE BERLINER ESR Spectroscopy in Membrane Biophysics, Springer, 2007

15.ZHOU L., BEUERMAN R.W. J Proteomics 2012, 75 nr. 13 p 3877.

16.C. F. CERRETANI, C. J. RADKE, Curr Eye Res. 39 nr. 6, 2014, p. 580. 17.NEACSU, M.V., MATEI, I., MICUTZ, M., STAICU, T, PRECUPAS, A., POPA, V.T., SALIFOGLOU, A., IONITA, G. J.Phys. Chem. B, 120 nr. 18, 2016, p. 4258.

18.MATEI, I. ARICIU, A.M., NEACSU, M.V., COLLAUTO, A., SALIFOGLOU, A.IONITA, G., , J. Phys. Chem. B, 118 nr. 38, 2014, p.11238.

19.NEBBIOSO H., REGNO P., GHARBIYA M., SACCHETTI M., PLATEROTI R. LAMBIASE A., Int. J.Mol. Sci., 18 nr. 8, 2017,p. 1764 20.LEMA I., DURAN J A., Ophthalmology 112, 2005, p. 645

Mnauscript received: 3.05. 2018 